\title{
An Investigation of the Perceived Value of Shopping Tourism
}

\author{
Submitted to Journal of Travel Research
}

\author{
Miju Choi * \\ School of Hotel and Tourism Management \\ Faculty of Business Administration \\ The Chinese University of Hong Kong \\ Shatin, NT, Hong Kong SAR \\ Tel: +852-5329-4005 \\ E-mail: mijuchoi@baf.cuhk.edu.hk
}

\author{
Rob Law \\ School of Hotel and Tourism Management \\ Hong Kong Polytechnic University \\ 17 Science Museum Road, TST East, Kowloon, Hong Kong SAR \\ Tel: + 852-3400-2181 \\ E-mail: rob.law@polyu.edu.hk
}

\section{Cindy Yoonjoung Heo}

Revenue Management

Ecole hôtelière de Lausanne

HES-SO/University of Applied Sciences Western Switzerland,

Route de Cojonnex 18, 1000 Lausanne 25, Switzerland

Tel: + 41-21-785-1111

E-mail: Cindy.HEO@ehl.ch 


\title{
An Investigation of the Perceived Value of Shopping Tourism
}

\author{
Abstract \\ Managing shopping risk is a prerequisite to ensuring business prosperity in shopping \\ destinations, as risk is likely to influence perceived value and the choice of future shopping \\ destinations. Previous studies have shown that enhancing trust is a means of avoiding or \\ minimizing perceived (shopping) risk. Increased trust is expected to reduce shopping risk and \\ ultimately foster the impression of a shopping destination as reliable. Despite its important \\ role, trust has received limited, if any, attention in shopping- and tourism-related research. As \\ shopping behavior while traveling abroad differs from ordinary shopping in one's home \\ country, tourists’ shopping activities require in-depth research grounded in psychological \\ theory. This study aimed to examine the influence of trust in a shopping destination on the \\ value of that destination as perceived by tourist shoppers. The findings suggest that trust in a \\ shopping destination positively influences perceptions of the destination's value in every \\ value category.
}

Keywords: shopping tourism, shopping tourist, perceived value, trust 


\section{Introduction}

Shopping has been a key tourism activity for decades. A number of studies have emphasized the importance of shopping to tourists, especially souvenir shopping (Lloyd, Yip, and Luk 2011; Wong and Wan 2013; Yüksel and Yüksel 2007), and shown that shopping offers a "means of experiencing a local culture" (Hsief and Chang 2006, 3). These studies have documented not only the economic effects of tourist shopping behavior, but also its psychological and social benefits. The importance of shopping has been suggested to be increasing relative to other leisure activities, and scholars have noted that it is now among the forces driving destination choice (Saayman and Saayman 2012; Timothy 2005). For example, the World Tourism Organization (UNWTO) (2014) has declared that shopping and gastronomy are emerging factors influencing destination choice. According to the UNWTO (2014), approximately $80 \%$ of Chinese tourists visited the Spanish city of Madrid for shopping purposes. These shopping tourists were found to stay longer (4.7 days on average) than leisure tourists (3.7 days on average). Leisure tourists spent approximately US\$511 each during their stay, whereas shopping tourists spent around US\$644 per capita (UNWTO 2014). These findings are consistent with Rosenbaum and Spears’s (2005) observation that compared with leisure tourists, shopping tourists spend up to three to four times more money while on vacation.

Yüksel and Yüksel (2007) also stated that managing shopping risk is vital to ensure the prosperity of the shopping industry in a given tourist destination, as risk is likely to influence tourists' perceived value and destination choice. This is linked with the basic human tendency to embrace pleasure and avoid pain. The Regulatory-focus Theory (RFT), 
proposed by Higgins (1997), explains the decision-making process in terms of two orientations of regulatory focus: promotion and prevention. The theory implies that if tourists perceive shopping risk while interacting with salespeople (e.g., a perceived lack of integrity or benevolence) or external shopping risk (reduced product quality/reputation, compromised transaction security, etc.), they reorient their regulatory focus toward prevention and withdraw from active engagement in shopping activities. Therefore, national tourism organizations (NTOs) and destination marketing organizations (DMOs) should seek to minimize potential shopping risk by pinpointing the components of shopping-destination trust (SDT) and, more importantly, determining how these components influence perceived value. Practitioners such as travel agencies, airline companies, and retailer associations should also use these findings to develop marketing strategies and promote destinations/products/services by highlighting and cultivating the key components of SDT. This is expected to reduce shopping risk and ultimately lead consumers to regard a shopping destination as reliable.

Despite their importance, the relationship between trust and perceived value have received limited attention in shopping- and tourism-related research. As shopping behavior while traveling abroad differs from ordinary shopping in one’s home country, tourists’ shopping activities require in-depth research grounded in psychological theory. Therefore, this study aimed to investigate SDT and perceived value from the perspective of RFT. More specifically, the study was guided the following objectives: (1) to investigate the dimensions of SDT, (2) to examine the effects of SDT on perceived value, and (3) to measure the moderating effect of gender on the proposed relationships. 


\section{Literature Review}

\section{Shopping Tourism and Shopping Risk}

Shopping tourism is "a contemporary form of tourism fostered by individuals for whom purchasing goods outside of their usual environment is a determining factor in their decision to travel” (UNWTO 2014, 13). Although shopping tourism is a fairly recent concept, a number of shopping studies have been conducted by tourism researchers in areas such as (1) souvenir shopping (Decrop and Masset 2014; Kong and Chang 2012; Swanson and Timothy 2012), (2) air passengers’ shopping motivation/duty-free shopping (Chung, Wu, and Chiang 2013; Doong, Wang, and Law 2012; Lin and Chen 2013), (3) the typology/segmentation of shopping tourists (Choi, Heo, and Law 2016; Hu and Yu 2007), and (4) tourists’ perceptions of shopping/shopping risk (Sirakaya-Turk, Ekinci, and Martin 2015; Tosun, Temizkan, Timothy, and Fyall 2007; Yüksel and Yüksel 2007). In the marketing literature, scholars have emphasized the potential influence of shopping risk on consumers’ purchasing behavior (Lim 2003; Sonmez and Graefe 1998). Yüksel and Yüksel (2007) stated that when consumers feel unsafe or threatened while shopping, they unconsciously formulate a negative impression of the shopping destination and become reluctant to continue shopping. That is, the greater the shopping risk consumers perceive, the less likely they are to shop and the more likely they are to turn to other activities.

Previous studies have identified several types of shopping risk, with one of the most widely used systems of categorization proposed by Jacoby and Kaplan (1972). Those authors introduced five types of perceived risk: (1) financial risk (e.g., monetary loss), (2) performance risk (e.g., product malfunction), (3) physical risk (e.g., the possibility that 
products “may be [or become] harmful or injurious to individuals’ health” [Jacoby and Kaplan 1972, 384]), (4) psychological risk (e.g., incompatibility between an unfamiliar brand and a shopper's self-image or self-concept, and (5) social risk (e.g., the likelihood that others will hold negative perceptions of shoppers as a result of their purchasing a particular product). Building on Jacoby and Kaplan’s (1972) framework, scholars have proposed additional types of shopping risk, such as time-loss risk (Darley and Smith 1995; McCorkle 1990), privacy risk (Graphic, Visualization, and Usability Center 1999; Jarvenpaa and Todd 1996), and source risk/information risk (i.e., risks to shoppers’ security and privacy) (McCorkle 1990).

Synthesizing previous studies, Yüksel and Yüksel $(2007,705)$ divided shopping risk into two categories: internal shopping risk, which "emanates from customer-salespersons interaction” (e.g., the risk of being tricked by the salesperson or receiving inadequate treatment from the salesperson), and external shopping risk, which stems not from customersalesperson interaction but from external factors (e.g., the risk of disease/infection, suffering an accident, or encountering violent behavior). Yüksel and Yüksel (2007) then examined the effects of internal and external shopping risk, respectively, on tourists’ emotions, satisfaction, and expressed loyalty intentions. Internal shopping risk was found to have a statistically significant influence on satisfaction, but the effect of external shopping risk on satisfaction was not found to be significant. In addition, internal/external shopping risk was shown to have a negative influence on expressed loyalty intentions. DMOs and NTOs seeking to attract tourists were thus recommended to promote tourist shopping destinations as safe places by stressing their political stability (e.g., the unlikelihood of coups and strikes), their safety (e.g., 
low crime rate, non-susceptibility to terrorist attacks), and the integrity/benevolence of local retail businesses.

\section{Shopping Destination Trust}

Minimizing risk is regarded as a prerequisite for business prosperity (Pizam, Tarlow, and Bloom 1997; Yüksel and Yüksel 2007). Previous studies have indicated that fostering trust is a means of avoiding or minimizing perceived (shopping) risk (Kim, Ferrin, and Rao 2008; Lim 2003). Scholars have explored the relationship between trust and perceived (shopping) risk in the context of electronic commerce, particularly Internet shopping, which inevitably carries high levels of uncertainty due to the lack of interaction between consumers and sellers. As a result, consumers are required to rely on the information given by sellers.

Cheung and Lee (2000) found that trust in Internet stores is affected by two factors: the trustworthiness of the Internet seller (security control, privacy control, integrity, and competence) and the external environment (i.e., third-party recognition and other relevant legal frameworks). Another study of trust and perceived risk in electronic-commerce contexts yielded similar results. Kim et al. (2008) found that the antecedents of trust comprised information quality, privacy protection, security protection, the presence of a third-party seal, a positive reputation, and consumers' disposition to trust. They also found that trust negatively affects the perceived risk of a transaction and positively affects consumers’ intention to purchase. Consistent with Cheung and Lee’s (2000) findings, they found that trust played a key role in reducing perceived risk. In addition, a number of scholars have concluded that fostering trust is a key means of alleviating perceived risk and influencing purchase intention (Lewis and Weigert 1985). 
Scholars have generally regarded trust as a multidimensional construct, although they have held different views of its dimensions. Some scholars have argued that trust has three dimensions: benevolence, integrity, and competence (Cheung and Lee 2006; Hawes, Rao, and Baker 1993; Swan, Bowers and Richardson 1999). Others have suggested four dimensions: benevolence, integrity, competence, and predictability (Benassi 1999; Bhimani 1996; Su and Manchala 1997). Various other dimensions (e.g., transaction security, product, information content, liking) have also been suggested (Camp 2001; Chow and Holden 1997). As these studies have focused on electronic commerce, the dimensions proposed have been closely related to seller characteristics. In short, the level of trust has been found to rely heavily on the degree of trustworthiness of the seller.

Choi, Law, and Heo (2016) emphasized tourists’ trust in a shopping destination and highlighted the need to identify its dimensions, as tourists are likely to attach more value to trust when choosing a holiday destination for shopping purposes than when engaging in ordinary shopping activities in their home country. Specifically, tourists are concerned with several factors, such as the reputation of the destination, the benevolence of local retailers, integrity (e.g., "whether the destination provides a shopping environment consistent with that being advertised” [Choi et al. 2016, 498]), and even transaction security. Therefore, Choi et al. (2016) proposed a measurement scale to identify the dimensions of SDT and determine which are particularly important. A case study in a Hong Kong setting was examined using a quantitative research method. Following the approach to scale development suggested by Churchill (1979) and Hinkin (1995), which has been widely used in the marketing research, an SDT scale was developed. The findings revealed that SDT has the following nine 
dimensions: competence, integrity, benevolence, ability, product, transaction security, predictability, reputation, and liking. Ability, integrity, benevolence, and liking were found to be the most important dimensions of SDT. Unlike previous studies of trust in electronic commerce, the SDT scale treated tourist destination as an object and integrated characteristics of the seller and product with security concerns and consumers' expectations (e.g., predictability). Interestingly, liking was also found to be a core dimension.

Adopting the construct of SDT proposed by Choi et al. (2016), the current study further explores the effects of SDT on tourists' perceptions of value, using an RFT framework. This theory, proposed by Higgins (1997), explains intuition in terms of people's perceptions during the decision-making process. RFT is a goal-pursuit theory based on two regulatory-focus orientations (promotion and prevention). Higgins (1997) further stated that RFT is based on the principle that people seek pleasure (i.e., gain) but avoid pain (i.e., loss). People unconsciously direct their promotion focus to maximize pleasure (e.g., hope and accomplishment) and adjust their prevention focus to minimize pain (e.g., loss) during decision making. Therefore, RFT was considered to provide a suitable theoretical framework for analysis of shopping tourists' perceptions of value in the current study. As shopping tourists travel primarily to shop, their goal is likely to obtain a satisfactory shopping experience. They thus adjust their regulatory focus when deciding on a holiday destination. Specifically, they likely favor trustworthy shopping destinations associated with very little risk, which provide a pleasant shopping experience and thereby enhance tourists' perceptions of value in multiple dimensions (e.g., emotional, social, and functional value). RFT was used in this study to connect trust, which reduces shopping-destination risk, with perceived value 
during shopping trips.

\section{Perceived Value}

Perceived value is defined as “the consumer's overall assessment of the utility of a product (or service) based on perceptions of what is received and what is given” (Zeithaml 1988, 14). Perceived value has gained increasing attention from both practitioners and academics. From a practitioner's perspective, perceived value relates to marketing strategies such as (cross-cultural) market segmentation, product differentiation, and resource allocation (Furrer, Liu, and Sudharshan 2000). Meanwhile, academics have investigated the antecedents of perceived value (e.g., service/experience quality, image, involvement, trust, motivation, tourist experience) and its consequences (e.g., satisfaction, behavioral intention, purchase intention, loyalty, and willingness to recommend). They have also examined these relationships using a means-end model (Chen and Tsai 2008; Gallarza and Saura 2006; Yen and Teng 2015).

Two main approaches to perceived value have been taken: unidimensional and multidimensional. Some scholars have regarded perceived value as a unidimensional concept, emphasizing economic utility in addition to the trade-off between the benefits obtained (e.g., customer utility) and that, which is given or sacrificed (e.g., price, time, effort) (Babin, Darden, and Griffin 1994; Holbrook 1994; Sheth, Newman, and Gross 1991). However, the unidimensional approach has been criticized for its failure to integrate various aspects of emotional state and external conditions that affect cognition, affect, and behavior (Sanchez, Callarisa, Rodriguez, and Moliner 2006). A multidimensional approach overcomes this limitation, allowing researchers to explore the factors underlying the phenomenon and gain a 
deeper understanding of consumer behavior (Sheth et al. 1991; Sweeney and Soutar 2001).

Table 1 provides details of several studies in which a multidimensional approach to perceived value was taken. These studies distinguished between functional aspects (e.g., quality and economic value) and affective aspects (e.g., emotional value). Sheth et al. (1991) analyzed perceived value and its dimensions with reference to cigarette smoking. The findings revealed that five dimensions, including social, emotional, functional, epistemic, and conditional value, were related to consumers’ 1) purchase decision (e.g., to buy or not to buy), 2) choice of product type (e.g., type A or B), and 3) choice of brand (e.g., brand A or B). More specifically, functional value was found to have the strongest influence on consumer choice, while social value was most closely associated with the choice of product type. The findings reported by Sheth et al. (1991) provide in-depth insights into consumer behavior. According to Sheth et al. (1991), functional value consists of reliability, durability, and price.

However, Dodds, Monroe, and Grewal (1991) argued that reliability and durability are the main components of quality/performance and distinct from price. In sum, functional value is understood to have two key components: quality/performance and price. Dodds et al. (1991) also pointed out that these components have opposing effects on perceived value: perceived value tends to be positively affected by quality but negatively affected by price. The researchers thus asserted that quality/performance and are distinct.

$$
\text { *** Place Table } 1 \text { here *** }
$$

Synthesizing previous studies, Sweeney and Soutar (2001) developed a perceivedvalue scale for durable goods, known as PERVAL. The scale was based on the six 
consumption-value dimensions proposed by Sheth et al. (1991). Through a focus-group process, epistemic and conditional value were excluded due to irrelevancy and replaced with two subcomponents of functional value. The final PERVAL scale consisted of four distinct dimensions: emotional value, social value, functional value (quality/performance), and functional value (price/value for money) (Sweeney and Soutar, 2001).

Later, Sanchez et al. (2006) developed a scale measuring perceived value during the experience of purchasing a tourism product, known as GLOVAL. Unlike conventional measurement scales, GLOVAL measures the perceived value of both the consumption experience (i.e., interaction with travel agency) and the purchase experience (i.e., functional value and price of tourism product). Based on PERVAL (Sweeney and Soutar, 2001), further components of functional value were specified, such as price, product quality, interaction with travel-agency personnel (professionalism), and travel agency (installations). Meanwhile, Petrick (2002) called for a new scale measuring the perceived value of intangible products/services due to their unique characteristics of intangibility, inseparability, perishability, variability, etc. Based on Zeithmal’s (1988) theoretical model of service, Petrick’s (2002) resulting SERV-PERVAL scale comprised behavioral price, monetary price, emotional response, quality, and reputation.

The PERVAL scale was used in the current study for the following reasons. First, shopping tourism entails the purchasing of products during travel. PERVAL was originally developed to measure the perceived value of durable goods (Sweeney and Soutar 2001). As most shopping items are tangible goods such as clothes, shoes, and accessories, PERVAL was expected to be an appropriate measurement scale. PERVAL enabled exploration of emotional 
value (e.g., “shopping trips make me happy”), social value (e.g., "shopping trips make me feel accepted by my peer group”), and subcomponents of functional value in the context of shopping trips. In addition, PERVAL has been widely used and verified in tourism, retail, and consumer studies.

\section{Hypothesis Development}

Trust is "a set of specific beliefs dealing primarily with the benevolence, competence, and integrity of another party” (Chiu, Hsu, Lai, and Chang, 2012, p. 836). In the context of (online) shopping, trust is the expected willingness to engage in a transaction, along with internal and external risk (Lee and Turban, 2001). Prior research examined the consequences of trust, such as perceived value, purchase intention and satisfaction (Hosmer, 1995; Hwang and Kim, 2007). Kim, Xu and Gupta (2012) confirmed the effect of perceived trust on purchase intention mediated by perceived value across both potential and repeat consumers. Similarly, Ponte, Carvajal-Trujillo and Escobar-Rodriguez (2015) found that trust in an online seller (e.g., a tourism product website) positively affected consumers’ perceived value.

Synthesizing prior findings, this study is based on the assumption that SDT positively influences tourists’ perceived value during shopping trips. Trust in a shopping destination may reduce shopping risk, making tourists feel more comfortable. Once tourists perceive a shopping destination to be a reliable place to shop, the perceived value of a shopping trip will increase. Based on empirical studies, the following hypotheses were proposed.

- Hypothesis 1 (H1): SDT positively influences tourists’ perceptions of emotional value.

- Hypothesis 2 (H2): SDT positively influences tourists’ perceptions of social value.

- Hypothesis 3 (H3): SDT positively influences tourists’ perceptions of functional value 
(quality/performance).

- Hypothesis 4 (H4): SDT positively influences tourists’ perceptions of functional value (price/value for money).

As shopping has been shown to differ by gender, researchers have shown interest in identifying the impact of gender on information processing and shopping behavior (Kellaris and Altsech, 1992; Meyers-Levy and Maheswaran, 1991; Yalch and Spangenberg, 1990). Gender has also been used as a moderator in the marketing literature. Kolyesnikova, Dodd and Wilcox (2009) used gender as a moderator of reciprocal consumer behavior. They confirmed that shopping perceptions and shopping behavior differed by gender. Similarly, Sun and Zhang (2006) confirmed the following differences in shopping behavior between genders: (1) males were more concerned with functional value (e.g., quality and price) and (2) females emphasized emotional value. This implies that males perceive shopping as a practical task to complete, whereas females consider shopping a form of leisure and entertainment (Gefen and Straub, 1997; Venkatesh and Morris, 2000). Based on these empirical findings, the following hypotheses were proposed.

- Hypothesis 5 (H5): gender moderates the relationship between SDT and tourists' perceptions of emotional value.

- Hypothesis 6 (H6): gender moderates the relationship between SDT and tourists' perceptions of social value.

- Hypothesis 7 (H7): gender moderates the relationship between SDT and tourists' perceptions of functional value (quality/performance).

- Hypothesis 8 (H8): gender moderates the relationship between SDT and tourists' 
perceptions of functional value (price/value for money).

Figure 1 shows the conceptual framework.

$$
\text { *** Place Figure } 1 \text { here *** }
$$

\section{Methods}

A four-section questionnaire was developed to obtain quantitative data. The first section comprised questions on the perceptions of value held by shopping tourists. The measurement items were adopted from PERVAL developed by Sweeney and Soutar (2001). PERVAL comprises 19 items in 4 dimensions (emotional value, social value, functional value [quality/performance], and functional value [price/value for money]). As PERVAL was initially developed to measure the perceived value of durable goods, the items were modified to fit the context of shopping tourism. The respondents were asked to indicate their level of agreement with each item on a 7-point Likert scale: 1 = strongly disagree, 2 = disagree, $3=$ somewhat disagree, 4 = neutral, $5=$ somewhat agree, 6 = agree, and $7=$ strongly agree.

The second section comprised questions related to SDT. The measurement items were adopted from Choi et al. (2016), who developed a scale to measure consumers' trust in a shopping destination in Hong Kong. Following the approach suggested by Churchill (1979) and Hinkin (1995), an SDT scale was developed and validated. The scale integrated a wide range of attributes of trust verified in the shopping-tourism literature, comprising 42 items in 9 dimensions (benevolence, integrity, competence, predictability, ability, transaction security, reputation, product, and liking). As the measurement items were suited to the context of shopping tourism, no amendments were made. The respondents were asked to indicate their 
level of agreement with each item on a 7-point Likert scale: 1 = strongly disagree, 2 = disagree, 3 = somewhat disagree, $4=$ neutral, $5=$ somewhat agree, $6=$ agree, and $7=$ strongly agree.

The third section comprised questions related to travel activities (e.g., frequency of visits, items purchased, shopping expenditure per person during visit, accompanying parties, and duration of stay) to capture relevant information. The questions were adapted from those used by the Hong Kong Tourism Board (HKTB) (2014). The final section elicited demographic information. To help ensure the content validity of the measurement items, the initial version of the questionnaire was sent to a panel of experts for review. Three academics whose major research interests lay in "tourist shopping” and "tourism destinations" thoroughly assessed the representativeness and applicability of each item relative to the corresponding construct. Each item was rated on a 5-point Likert scale ranging from 1 ("totally inapplicable”) to 5 ("totally applicable”). Items with a mean value above 3.0 were retained. The panel of experts also suggested polishing the measurement items adopted from PERVAL and avoiding the use of academic terms such as "shopping tourism." For example, the statement "I enjoy shopping tourism," constructed to measure the perceived emotional value of a shopping destination, sounded awkward and ambiguous. It was thus revised to give the following statement: "I enjoy shopping trips.” As no specific comments were provided on SDT, no revisions were made. After the survey had been amended, the panel of experts reassessed the items and confirmed the validity of the survey. Sixty-one items in nine dimensions were retained. Appendix 1 shows the refined measurement items. 


\section{Data Collection}

Hong Kong was chosen as the data-collection site. A 2014 report revealed that shopping accounted for $61.7 \%$ of overnight visitors’ spending, followed by hotel bills (18.0\%), meals outside hotels (11.3\%), tours (0.3\%), entertainment (3.4\%), and other activities (5.3\%) (HKTB 2015). In addition, Hong Kong was ranked as Asia’s best shopping destination in 2013 (Global Blue 2014). The study aimed to examine the effect of SDT on tourists' perceptions of the value of shopping destinations. Therefore, it was considered important to obtain a particular sample of respondents, i.e., shopping tourists. Two screening questions were adapted from UNWTO (2014) and Choi et al. (2016). As shown in Figure 2a, the first dichotomous screening question asked the respondents to indicate the major purpose of their visit; that is, whether they "traveled to Hong Kong with the major purpose of shopping.” Only the respondents who answered “yes” were invited to answer the second question. The second screening question asked the respondents to state the top three major reasons for their trip to Hong Kong. The respondents who gave the answer "shopping” were treated as shopping tourists.

After the questionnaire was developed, a pilot test was conducted to check the reliability of the measurement items and assess the feasibility of the main data-collection methods. Well-trained undergraduate students majoring in tourism management were dispatched to various shopping sites to conduct a survey. Two hundred and thirty-nine usable questionnaires were obtained through convenience sampling. The results of a reliability test revealed that the coefficient for each dimension ranged between 0.888 and 0.967 , which exceeded the minimum cut-off of 0.7 (Hair, Black, Babin, and Anderson 2010). Although the 
coefficient met the criteria, a couple of problems were detected during the pilot test. For example, the respondents were confused by the second screening question, which appeared to repeat the first question. Most of the respondents believed that they were required to exclude "shopping" from their list of purposes because they had mentioned it in response to the first screening question. The students were required to repeatedly clarify the nature of the two questions. Therefore, the second screening question had to be either revised or deleted. The respondents who both answered 'yes' to the first question and indicated 'shopping' in response to the second question ('please state the top three travel activities in which you participated') were regarded as appropriate study targets.

After this minor revision, the main survey was conducted. Fifteen experienced undergraduate students approached tourists at tourist sites in three districts of Hong Kong [Kowloon (Hung Hom Station, Kowloon Park and others), Hong Kong Island (Times Square, Stanley Market, Prada Outlet/Horizon Outlet and others) and Lantau Island (Citygate Outlet and Hong Kong International Airport)]. The students briefly explained the purpose of the study to the tourists and invited them to participate. As a token of appreciation, each respondent received a free coffee/drink coupon after completing the survey.

Through convenience sampling, 768 surveys were collected. Inappropriate responses (e.g., incomplete surveys) were excluded, leaving 708 usable samples for further data analysis. The following results of a reliability test were deemed acceptable: emotional value (0.947), social value (0.905), functional value (price/value for money) (0.966), functional 
value (quality/performance) (0.941), benevolence (0.972), integrity (0.941), competence (0.944), predictability (0.968), ability (0.945), transaction security (0.961), reputation (0.962), product (0.972), and liking (0.952). Version 21.0 of the Statistical Package for the Social Sciences was used to conduct descriptive analysis and exploratory factor analysis (EFA) of the data. Analysis of Moment Structures 21.0 was used to perform the confirmatory factor analysis (CFA) and path analysis.

\section{Results}

\section{Sample Characteristics and Travel Activity}

Table 2 shows the profiles of the respondents. Gender was almost evenly distributed, with males comprising 56.4\% of the sample $(\mathrm{n}=399)$. Middle-aged respondents (between 36 and 65$)$ accounted for $65.3 \%$ of the sample $(n=463)$. Bachelor's degree holders made up $61.3 \%(n=434)$ of the respondents. The majority of the respondents were employed $(61.0 \%$, $n=432), 17.2 \%(n=122)$ were housewives, $8.6 \%(n=61)$ were students, $12.7 \%(n=90)$ were retired, and $0.4 \%(n=3)$ had other occupations. The respondents were divided into Chinese and non-Chinese groups, which were almost evenly distributed, at $48.6 \%(\mathrm{n}=344)$ and $51.4 \%(n=364)$, respectively. Just over half $(55.9 \%)$ of the respondents $(n=396)$ reported a household income of US\$5,001-10,000.

\footnotetext{
*** Place Table 2 here ***
}

The respondents' travel activities are shown in Table 3. Less than half (43.6\%) of the respondents $(n=309)$ had never previously visited Hong Kong, whereas 56.4\% were repeat 
visitors; 293 (41.4\%) had visited Hong Kong between one and three times. The main shopping items were garments/fabric/shoes, accounting for $22.9 \%$ of the sample, followed by jewelry/watches (19.8\%). In terms of shopping expenses per person for the entire trip, 23.7\% of the respondents $(n=168)$ spent US\$2,500-2,999.

$$
\text { *** Place Table } 3 \text { here *** }
$$

\section{Cross-validation}

The dataset $(\mathrm{n}=708)$ was randomly split into two subsamples. The first subsample (n = 354) was used for maximum-likelihood EFA, while the second subsample $(\mathrm{n}=354)$ was subjected to CFA. Table 4 shows the results of the EFA (with Promax rotation). The result of the Kaiser-Meyer-Olkin test (0.911) indicated the sampling adequacy of each variable in the model (Hair, Black, Babin, and Anderson 2010). Bartlett’s test of sphericity was significant $\left[\chi^{2}=28,294.083(\mathrm{df}=1,953 ; \mathrm{p}<0.001)\right]$. Four factors were extracted for perceived value and nine factors for SDT, which together explained $80.076 \%$ of the total variance. Cronbach's alpha exceeded 0.70, the cut-off suggested by Hair et al. (2010), indicating that the 13 factors were reliable.

\section{*** Place Table 4 here ***}

Next, CFA was conducted with the second subsample $(n=354)$. Table 5 shows the standardized maximum likelihood loading and fit statistics. As all of the regression weights were significant, no modifications were made. Finally, 61 items with the 13 factors were retained. The following indicators of model fit were obtained: $\chi^{2}=4,945.473(\mathrm{df}=1,691 ; \mathrm{p}<$ 0.001), comparative fit index $(\mathrm{CFI})=0.891$, normed-fit index $(\mathrm{NFI})=0.844$, non-normed fit 
index $(\mathrm{NNFI})=0.882$, parsimony NFI $(\mathrm{PNFI})=0.779$, and root mean square error of approximation $($ RMSEA $)=0.074$. The values of CFI, NFI, NNFI, and PNFI ranged between 0 and 1, where "values close to 1 indicate better model fit" (Kalliath, Bluedorn, and Gillespie 1999, 152). "The error measures should not exceed 0.1 and ideally lie between 0.05 and 0.08 given that at least some error can be expected” (Yüksel and Yüksel 2007, 708). Therefore, the null model obtained was believed to have an acceptable fit.

Convergent validity was measured in terms of average variance extracted (AVE) and composite reliability. As shown in Table 5, the AVE for all scales exceeded 0.50, the cut-off suggested by Fornell and Larcker (1981), and composite reliability exceeded 0.80, the cut-off suggested by Netemeyer, Bearden, and Sharma (2003). Discriminant validity was also assessed by comparing correlation estimates between constructs. The estimates of variance extracted for individual constructs exceeded the squared correlation between the constructs (refer to Table 6). Therefore, the convergent validity and discriminant validity were considered to be high.

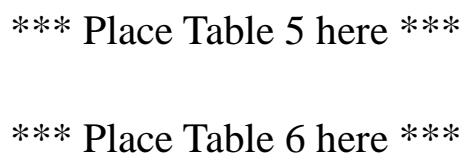

\section{Measurement Quality}

Next, two subsamples were subjected to first-order CFA, testing the relationships between 13 latent variables and 61 observed indicators. As shown in Table 7, the model fit was acceptable: $\chi^{2}=5,215.853, \mathrm{df}=1,691, \mathrm{p}<0.001, \mathrm{CFI}=0.935, \mathrm{NFI}=0.907, \mathrm{NNFI}=$ $0.930, \mathrm{PNFI}=0.838$, and RMSEA $=0.054$. As all of the regression weights were significant, 
no modifications were made. The AVE values for all scales ranged between 0.708 and 0.923 , exceeding the cut-off value of 0.50 , and all composite-reliability values exceeded 0.80 . Therefore, convergent validity was considered to be high. As shown in Table 8, discriminant validity was ascertained by measuring the inter-correlation between the 13 latent variables. The diagonal values were greater than the highest correlation values for individual variables: liking (0.932), product (0.924), predictability (0.915), reputation (0.900), competence (0.863), functional value (quality/performance) (0.854), emotional value (0.884), transaction security (0.928), functional value (price/value for money) (0.939), integrity (0.895), social value (0.841), benevolence (0.960), and ability (0.904). Therefore, discriminant validity was considered to be high.

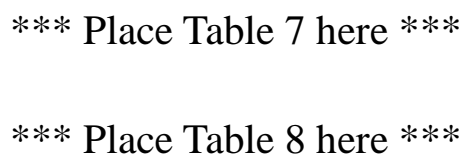

Subsequently, second-order CFA was performed to assess the factor structure obtained from the first-order CFA of the measurement model. As shown in Table 9, all of the indicators demonstrated a significant factor loading, exceeding 0.5 , and the model showed an acceptable fit to the data: $\chi^{2}=5,434.986, \mathrm{df}=1,750, \mathrm{p}<0.001, \mathrm{CFI}=0.932, \mathrm{NFI}=0.903, \mathrm{NNFI}=$ 0.929, PNFI $=0.864$, RMSEA $=0.055$. The AVE values for all of the scales ranged between 0.536 and 0.882 , and all of the values for composite reliability exceeded 0.80 . Therefore, convergent validity was high. In addition, Table 10 displays the results for discriminant validity, which was high for all types of value: social value (0.841), functional value (quality/performance) (0.854), emotional value (0.884), functional value (price/value for money) (0.939), and SDT (0.732). 


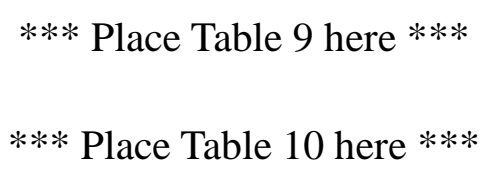

\section{Hypothesis Testing}

The hypothesized relationships were assessed using structural equation modeling. Overall, the structural model revealed an adequate model fit: $\chi^{2}=6,149.273, \mathrm{df}=1,756, \mathrm{p}<$ $0.001, \mathrm{CFI}=0.919, \mathrm{NFI}=0.890, \mathrm{NNFI}=0.916, \mathrm{PNFI}=0.854$, and RMSEA $=0.059$. Table 11 displays the standardized theoretical paths linking SDT, emotional value, social value, functional value (price/value for money), and functional value (quality/performance). H1 suggested that SFT would positively affect the emotional value perceived by shopping tourists. This relationship was supported by the corresponding estimate: $\beta=0.326(t=7.925$, $\mathrm{p}<0.01)$. H2 suggested that SDT would be directly related to social value. The path was supported by the corresponding estimate: $\beta=0.226$ ( $t=5.479, \mathrm{p}<0.01)$. H3 suggested that SDT would positively affect functional value (quality/performance). This was supported by the corresponding estimate: $\beta=0.266$, $(\mathrm{t}=6.610, \mathrm{p}<0.01)$. H4 suggested that SDT would be directly related to functional value (price/value for money). This path was supported by the corresponding estimate: $\beta=0.216$ ( $t=5.335, p<0.01$ ). In summary, all of the causal paths specified in the structural model were statistically significant.

*** Place Table 11 here ***

Table 12 presents the results for the moderating effects. H5-H8 held that gender would moderate the relationship between SDT and each type of perceived value. However, three of these four hypotheses were statistically insignificant. H5 (female: $0.283, \mathrm{p}<0.01$, 
male: 0.260, p < 0.01; z-score: -0.333, $p>0.1$ ), H6 (female: 0.159, $\mathrm{p}<0.01$, male: $0.207, \mathrm{p}<$ 0.01; z-score: 0.707, $p>0.1$ ), and H8 (female: 0.207, p < 0.01; male: 0.258, p < 0.01; zscore: $0.566, p>0.1$ ) were not supported. The relationship between SDT and functional value (quality/performance) was moderated by gender (female: 0.072, $\mathrm{p}<0.1$, male: 0.393 ; $\mathrm{p}<$ 0.01, z-score: $4.208, p<0.01)$. Therefore, $\mathrm{H} 7$ was supported. These findings imply that male tourists’ perceptions of functional value (quality/performance) are more strongly influenced by trust in the shopping destination.

$$
\text { ** Place Table } 12 \text { here ** }
$$

\section{Conclusions}

This study examined trust in the shopping destination as an antecedent of shopping tourists' perceptions of value. The proposed model was built on the basis of an RFT framework (Higgins 1997), according to which people tend to manipulate their regulatory focus to maximize pleasure and minimize pain, eventually leading to goal attainment (Higgins 1997). Although Higgins's theory was developed in relation to decision making, the current study indicated that RFT is also capable of explaining the effects of SDT on shopping tourists’ perceptions of value. Based on RFT, tourists tend to visit more trusted shopping destinations to maximize pleasure (through shopping) and minimize risk, which eventually positively affects their perceptions of value. Consequently, their main goal—a pleasant shopping experience-is achieved. According to the study's findings, SDT has positive effects on each dimension of perceived value (emotional value, social value, functional value [quality/performance], and functional value [price/value for money]). This is consistent with 
the results reported in the trust literature, which suggest that a high level of trust alleviates potential (shopping) risk during Internet shopping and eventually influences perceived value (Chong, Yang, and Wong 2003; Kim, Chung, and Lee 2011; Ranaweera and Prabhu 2003; Sirdeshmukh, Singh, and Sabol 2002).

The findings of this study also broaden shopping tourism research. Although shopping tourism has been widely explored, shopping has mainly been treated as an ancillary activity during such trips (Kozak 2016; Meng and Xu 2012; Park and Reisinger 2009), and in-depth research on shopping destinations has been limited. Instead, scholars have focused on tourists' shopping behavior in terms of motivation (Huang and Hsu 2005; Tosun et al. 2007), satisfaction (LeHew and Wesley 2007), souvenir purchasing (Decrop and Masset 2014; Kong and Chang 2012), etc. Adapting the SDT scale developed by Choi et al. (2016), this study confirmed the dimensions of trust in a shopping destination (benevolence, integrity, competence, predictability, ability, transaction security, reputation, nature of product, and liking). As the SDT scale is relatively new, few scholars have used it to date. In this study, all of the dimensions were shown to be relevant, and even more importantly, "ability," "transaction security," and "benevolence" were found to be the most significant. The findings of this study are thus expected to enrich future shopping-tourism research.

In addition, the topic of perceived value is gaining increasing attention in tourism research, and a number of studies have explored the antecedents (e.g., destination image, novelty, hedonics, motivation, involvement) (Cheng and Lu, 2013; Prebensen et al., 2013) and consequences (e.g., behavioral intention to revisit, satisfaction) of perceived value, along 
with the relationships between these variables (Bajs, 2015; Chen and Chen, 2010; Eid and ElGohary, 2015b; Jin, Lee, and Lee, 2015). The current study extended previous work on perceived value in tourism by investigating the influence of trust on the perceptions of value held by shopping tourists. Most studies of perceived value have treated the variable as unidimensional (Bajs, 2015; Cheng and Lu, 2013, Prebensen et al., 2013); whereas this study used a multidimensional measure of perceived value (i.e., emotional value, social value, functional value in terms of quality/performance and functional value in terms of cost/value for money). The study's findings confirmed the effect of trust in shopping destination on perceived value, based on RFT.

\section{Practical Implications}

The results of this study have several practical implications. They confirm the dimensions of SDT suggested by Choi et al. (2016). “Ability,” "benevolence,” "transaction security" and "reputation” were found to have the strongest influence on SDT. Studies of trust have also suggested that "ability” and "benevolence” are core dimensions of trust in retailers (Gefen and Straub, 2004; Lau and Lee, 1999).

First, NTOs may utilize the (key) dimensions when developing branding plans. For example, the dimensions could be used as sub-themes measuring the trustworthiness of a shopping destination, with "ability” and “competence” reflecting a competent shopping destination with service excellence; "benevolence” emphasizing sincere and caring retailers; “transaction security” integrating the safe transmission of personal information with sufficient technical capacity; and "reputation” representing positive word-of-mouth. The 
(key) dimensions are connected to form an image of a trustworthy shopping destination. In the case of Hong Kong, this could be expressed in the form of a new brand slogan such as “Trust lies in Hong Kong.” Each dimension can be highlighted through media channels. The HKTB and most NTOs operate official websites and social networking sites. Video clips and photographs capturing attractive shopping landmarks and various products can demonstrate the aspects of “ability” and “competence.” In addition, interviews with tourists can be uploaded to share their shopping experiences in Hong Kong. Positive hospitality and service experiences reported by the tourists can explain "benevolence” and "reputation.” “Transaction security” is also a concern among tourists. The HKTB is advised to clarify its regulations at a government level to prevent transaction accidents. This will help to reduce transaction security concerns.

Second, the HKTB can use the aforementioned dimensions to complement its QTS Scheme. The HKTB launched the QTS Scheme in 1999 to enhance the quality of tourism services in the retail sector and the hospitality sector (e.g., restaurants and accommodation). Tourists and local residents recognize QTS-accredited stores/restaurants through a QTS decal, which signifies QTS status. To attain and/or maintain QTS certification, a merchant should obtain an acceptable number of points in a QTS assessment. The criteria for the retail sector comprise five contributors: environment, product, process, people and system. However, the conventional QTS Scheme concentrates on product information, neglecting the assessment of trust-related factors. It is expected that he QTS Scheme can be improved by adding dimensions/elements of SDT such as competence, integrity, product, benevolence and 
transaction security. The outcome may offer guidance for tourists on where to shop, eat and stay. It is eventually expected to strengthen Hong Kong's reputation as a "shoppers' paradise” and the "culinary capital of Asia."

\section{Limitations and Suggestions for Future Research}

This study had the following limitations. First, it lacked generalizability due to the restricted sample population and number of study sites, as well as the use solely of convenience sampling. Future researchers should consider using other sampling methods, such as quota and stratified sampling. Second, as research on perceived value in the context of shopping tourism is limited, mixed methods are recommended for future research. In-depth interviews with shopping tourists may give researchers a more in-depth understanding of factors related to perceived value and SDT. Last but not least, gender was found to moderate only one of the four relationships suggested in this study. Future research should consider testing other moderating variables, such as previous experience (first-time visitors vs repeat visitors), distance (long haul vs short haul), and nationality (Asian vs non-Asian). In conclusion, however, the findings of this study are expected to help broaden the literature on shopping tourism. 


\section{Appendix 1 Refined Measurement Items}

Constructs and Items

\section{Emotional value (EV)}

EV1 I enjoy a shopping trip.

EV2 The thought of a shopping trip makes me want to experience it.

EV3 I feel relaxed during a shopping trip.

EV4 A shopping trip makes me feel good.

\section{Social value (SV)}

SV1 A shopping trip gives me pleasure.

SV2 Joining a shopping trip helps me feel accepted by the peer group that I engage with.

SV3 Joining a shopping trip improves the way others perceive me.

SV4 Joining a shopping trip makes a good impression on other people.

SV5 Joining a shopping trip provides me with social approval.

\section{Functional value (cost/value for money)}

COST1 The costs of a shopping trip are reasonable.

COST2 A shopping trip offers better value for money than other trips.

COST3 A shopping trip has a good value for money.

COST4 A shopping trip is economical.

\section{Functional value (quality/performance)}

QUA1 Products purchased during a shopping trip have consistent quality.

QUA2 Products purchased during a shopping trip are well made.

QUA3 Products purchased during a shopping trip have acceptable quality standards.

QUA4 Products purchased during a shopping trip have poor workmanship.

QUA5 Products purchased during a shopping trip do not last a long time.

QUA6 Products purchased during a shopping trip have consistent performance.

\section{Benevolence (BN)}

BN1 Hong Kong retailers act in my best interest.

BN2 If I need help, Hong Kong retailers do their best to help me.

BN3 Hong Kong retailers are concerned about my well-being.

\section{Integrity (INT)}

INT1 Hong Kong provides a shopping environment consistent with that being advertised.

INT2 Hong Kong advertises shopping products that it does not offer.

INT3 Retail shop employees in Hong Kong are honest in their dealings with tourists.

INT4 Retail shop employees in Hong Kong are ethical.

\section{Competence (COM)}

COM1 Hong Kong is the best destination for a shopping trip.

COM2 Other shopping destinations are better than Hong Kong.

COM3 Hong Kong offers a better shopping environment than other destinations.

COM4 I can do my shopping more effectively in Hong Kong than in other destinations.

COM5 Hong Kong meets my shopping needs better than other shopping destinations.

COM6 I accomplish my shopping tasks in Hong Kong more easily than in other destinations.

\section{Predictability (PRE)}

PRE1 When I visit Hong Kong for shopping, I know exactly what to do.

PRE2 I can always correctly anticipate how Hong Kong will be as a shopping destination.

PRE3 Hong Kong does not offer consistent shopping quality for tourists.

PRE4 Hong Kong provides a consistent shopping environment.

PRE5 I cannot always be sure of the shopping environment in Hong Kong each time I visit.

PRE6 I know how Hong Kong is going to provide a shopping environment for me.

\section{Ability (AB)}


AB1 Hong Kong is a competent shopping destination.

AB2 Hong Kong as a shopping destination understands my shopping needs.

AB3 Hong Kong as a shopping destination knows my shopping needs.

AB4 Hong Kong as a shopping destination knows how to provide excellent service.

\section{Transaction Security (TS)}

TS1 Retail shops in

TS2 Retail shops in Hong Kong show great concern for the security of any transaction.

TS3 Retail shops in Hong Kong have sufficient technical capacity.

TS4 I am sure of the identity of retail shops in Hong Kong when I shop.

\section{Reputation (REP)}

REP1 Hong Kong has a good reputation as a shopping destination.

REP2 Hong Kong has an unreliable reputation as a shopping destination.

REP3 Other people have told me that Hong Kong is not a reliable place for a shopping trip.

REP4 Other people have told me that Hong Kong is a reliable place for a shopping trip.

REP5 Hong Kong has a reputation as a convenient shopping destination.

REP6 I have heard negative comments about Hong Kong as a shopping destination.

\section{Product (PRO)}

PRO1 Products purchased in Hong Kong are highly likely to be reliable.

PRO2 Products purchased in Hong Kong appear to have exquisite workmanship.

PRO3 Products purchased in Hong Kong appear to be of very good quality.

PRO4 I consider products purchased in Hong Kong to be very functional.

PRO5 Products purchased in Hong Kong are extremely likely to be dependable.

PRO6 Products purchased in Hong Kong seem to be durable.

\section{Liking (LK)}

LK1 I like Hong Kong as a shopping destination.

LK2 I prefer other shopping destinations over Hong Kong.

LK3 Hong Kong is my favorite shopping destination.

\section{References}


Babin, B. J., W. R. Darden., and M. Griffin. 1994. "Work and/or Fun: Measuring Hedonic and Utilitarian Shopping Value.” Journal of Consumer Research 20 (4): 644-56.

Benassi, P. 1999. “TRUSTe: An Online Privacy Seal Program.” Communications of the ACM 42 (2): 56-9.

Bhimani, A. 1996. "Securing the Commercial Internet." Communications of the ACM 39 (6): 29-35.

Camp, L. J. (2001). Designing for trust, trust, reputation and Security: Theories and practice. Berlin: Rino Falcone Springer-Verlang.

Chen, C. F., and F. S. Chen. 2010. “Experience Quality, Perceived Value, Satisfaction and Behavioral Intentions for Heritage Tourists.” Tourism Management 31 (1): 29-35.

Chen, C. F., and M. H. Tsai. 2008. "Perceived Value, Satisfaction, and Loyalty of TV Travel Product Shopping: Involvement as a Moderator.” Tourism Management 29 (6): 116671.

Cheung, C. M., and M. K. Lee. 2006. “Understanding Consumer Trust in Internet Shopping: A Multidisciplinary Approach.” Journal of the American society for Information Science and Technology 57 (4): 479-92.

Chi, T., and P. P. Kilduff. 2011. "Understanding Consumer Perceived Value of Casual Sportswear: An Empirical Study.” Journal of Retailing and Consumer Services 18 (5): 422-29.

Choi, M. J., C. Y. Heo., and R. Law. 2016. “Developing a Typology of Chinese Shopping Tourists: An Application of the Schwartz Model of Universal Human Values. Journal of Travel and Tourism Marketing 33 (2): 141-61.

Choi, M., R. Law., and C. Y. Heo. 2016. “Shopping Destinations and Trust-Tourist Attitudes: Scale Development and Validation.” Tourism Management 54: 490-501.

Chong, B., Z. Yang., and M. Wong. 2003. “Asymmetrical Impact of Trustworthiness Attributes on Trust, Perceived Value and Purchase Intention: A Conceptual Framework for Cross-cultural Study on Consumer Perception of Online Auction.” In Proceedings of the 5th International Conference on Electronic Commerce (pp. 213219). ACM.

Chow, S., and R. Holden. 1997. "Toward an Understanding of Loyalty: The Moderating Role of Trust.” Journal of Managerial Issues 9 (3): 275-98.

Chung, Y. S., C. L. Wu., and W. E. Chiang. 2013. “Air Passengers' Shopping Motivation and Information Seeking Behaviour.” Journal of Air Transport Management 27: 25-8. 
Churchill, G. A. 1979. “A Paradigm for Developing Better Measures of Marketing Constructs.” Journal of Marketing Research 16, 64-73.

Cronin, J. J., M. K. Brady., and Hult, G. T. M. 2000. “Assessing the Effects of Quality, Value, and Customer Satisfaction on Consumer Behavioral Intentions in Service Environments.” Journal of Retailing 76 (2): 193-218.

Darley, W. K., and R. E. Smith. 1995. “Gender Differences in Information Processing Strategies: An Empirical Test of the Selectivity Model in Advertising Response.” Journal of Advertising 24 (1): 41-56.

Decrop, A., and J. Masset. 2014. "This is a Piece of Coral Received from Captain Bob: Meanings and Functions of Tourist Souvenirs.” International Journal of Culture, Tourism and Hospitality Research 8 (1): 22-34.

Dodds, W. B., K. B. Monroe., and D. Grewal. 1991. "Effects of Price, Brand, and Store Information on Buyers' Product Evaluations.” Journal of Marketing Research 28 (3): 307-19.

Doong, H. S., H. C. Wang., and R. Law. 2012. "An Examination of the Determinants of Inflight Duty-free Shopping: Hedonic and Utilitarian Motivations.” International Journal of Tourism Research 14 (3): 303-6.

Eid, R., and H. El-Gohary. 2015. "Muslim Tourist Perceived Value in the Hospitality and Tourism Industry.” Journal of Travel Research 54 (6): 774-87.

Fornell, C., and D. F. Larcker. 1981. "Structural Equation Models with Unobservable Variables and Measurement Error: Algebra and Statistics.” Journal of Marketing Research 18 (3): 382-8.

Furrer, O., B. S. C. Liu., and D. Sudharshan. 2000. “The Relationships between Culture and Service Quality Perceptions Basis for Cross-cultural Market Segmentation and Resource Allocation.” Journal of Service Research 2 (4): 355-71.

Gallarza, M. G., and I. G. Saura. 2006. "Value Dimensions, Perceived Value, Satisfaction and Loyalty: An Investigation of University Students’ Travel Behaviour.” Tourism Management 27 (3): 437-52.

Gefen, D. 2000. Gender Differences in the Perception and Adoption of E-mail and Computermediated Communication Media: A Sociolinguistics Approach. The Encyclopedia of Library and Information Science. New York: Marcel Dekker, 139-53.

Gefen, D., and D. W. Straub. 1997. "Gender Differences in the Perception and Use of E-mail: An Extension to the Technology Acceptance Model.” MIS Quarterly 21 (4): 389-400.

Gill, D., B. Byslma., and R. Ouschan. 2007. “Customer Perceived Value in a Cellar Door 
Visit: The Impact on Behavioural Intentions.” International Journal of Wine Business Research 19 (4): 257-75.

Hair, J. F., W. C. Black., B. J. Babin., and R. E. Anderson. 2010. Multivariate data analysis 7th ed. Englewood Cliffs: Prentice Hall.

Hawes, J. M., C. P. Rao., and T. L. Baker. 1993. "Retail Salesperson Attributes and the Role of Dependability in the Selection of Durable Goods.” Journal of Personal Selling \& Sales Management 13, 61-71.

Higgins, E. T. 1997. “Beyond Pleasure and Pain.” American Psychologist 52 (12): 1280-300.

Hinkins, T. R. 1995. "A Review of Scale Development in the Study of Behavior in Organizations.” Journal of Management 21: 967-88.

Holbrook, M. B. 1994. "The Nature of Customer Value: An Axiology of Services in the Consumption Experience.” Service Quality: New Directions in Theory and Practice 21: 21-71.

Hong Kong Tourism Board. 2015. A statistical review of Hong Kong Tourism 2014. Hong Kong: Hong Kong Tourism Board.

Hosmer, L. T. 1995. "Trust: The Concept Link between Organizational Theory and Philosophical Ethics.” Academy of Management Review 20 (2): 379403.

Hsieh, A. T., and J. Chang. 2006. "Shopping and Tourist Night Markets in Taiwan.” Tourism Management 27 (1): 138-45.

Hu, B., and H. Yu. 2007. "Segmentation by Craft Selection Criteria and Shopping Involvement.” Tourism Management 28 (4): 1079-92.

Huang, S., and C. H. Hsu. 2005. "Mainland Chinese Residents' Perceptions and Motivations of Visiting Hong Kong: Evidence from Focus Group Interviews.” Asia Pacific Journal of Tourism Research 10 (2): 191-205.

Hwang, Y., and D. J. Kim. 2007. “Customer Self-service Systems: The Effects of Perceived Web Quality with Service Contents on Enjoyment, Anxiety, and E-trust.” Decision Support Systems 43 (3): 746-60.

Jacoby, J., and L. B. Kaplan. 1972. “The Components of Perceived Risk.” In SV-Proceedings of the Third Annual Conference of the Association for Consumer Research. eds. M. Venkatesan, Chicago, IL : Association for Consumer Research, Pages: 382-393.

Jarvenpaa, S. L., and P. A. Todd. 1996. "Consumer Reactions to Electronic Shopping on the World Wide Web.” International Journal of Electronic Commerce 1 (2): 59-88. 
Kalliath, T. J., A. C. Bluedorn., and D. F. Gillespie. 1999. “A Confirmatory Factor Analysis of the Competing Values Instrument.” Educational and Psychological Measurement 59 (1): $143-58$.

Kellaris, J. J., and M. B. Altsech. 1992. "The Experience of Time as a Function of Musical Loudness and Gender of Listener.” NA-Advances in Consumer Research.

Kim, D. J., D. L. Ferrin., and H. R. Rao. 2008. “A Trust-based Consumer Decision-making Model in Electronic Commerce: The Role of Trust, Perceived Risk, and Their Antecedents.” Decision Support Systems 44 (2): 544-64.

Kim, H. W., Y. Xu., and S. Gupta. 2012. "Which is More Important in Internet Shopping, Perceived Price or Trust?” Electronic Commerce Research and Applications 11 (3): 241-52.

Kong, W. H., and T. Z. Chang. 2012. "The Role of Souvenir Shopping in a Diversified Macau Destination Portfolio.” Journal of Hospitality Marketing and Management 21 (4): 357-73.

Kozak, M. 2016. "Bargaining Behavior and the Shopping Experiences of British Tourists on Vacation.” Journal of Travel and Tourism Marketing 33 (3): 313-25.

Lee, M. K. O., and E. Turban. 2001. “A Trust Model for Consumer Internet Shopping.” International Journal of Electronic Commerce 6 (1): 75-90.

LeHew, M. L., and S. C. Wesley. 2007. “Tourist Shoppers' Satisfaction with Regional Shopping Mall Experiences.” International Journal of Culture, Tourism and Hospitality Research 1 (1): 82-96.

Lewis, J. D., and A. Weigert. 1985. “Trust as a Social Reality.” Social Forces 63 (4): 967-85.

Lim, N. 2003. “Consumers’ Perceived Risk: Sources versus Consequences.” Electronic Commerce Research and Applications 2 (3): 216-28.

Lin, W. T., and C. F. Chen. 2013. "Shopping Satisfaction at Airport Duty-free Stores: A Cross-cultural Comparison.” Journal of Hospitality Marketing and Management 22 (1): 47-66.

Lloyd, A. E., L. S. Yip., and S. T. Luk. 2011. “An Examination of the Differences in Retail Service Evaluation between Domestic and Tourist Shoppers in Hong Kong.” Tourism Management 32 (3): 520-33.

McCorkle, D. E. 1990. “The Role of Perceived Risk in Mail Order Catalog Shopping.” Journal of Direct Marketing 4 (4): 26-35.

Meng, F., and Y. Xu. 2012. Tourism Shopping Behavior: Planned, Impulsive, or Experiential? 
International Journal of Culture, Tourism and Hospitality Research 6 (3): 250-65.

Meyers-Levy, J., and D. Maheswaran. 1991. "Exploring Differences in Males' and Females' Processing Strategies.” Journal of Consumer Research 18 (1): 63-70.

Netemeyer, R. G., W. O. Bearden., and S. Sharma. 2003. Scaling Procedures: Issues and Applications. Sage Publications: London

Park, K. S., and Y. Reisinger. 2009. "Cultural Differences in Shopping for Luxury Goods: Western, Asian, and Hispanic Tourists.” Journal of Travel and Tourism Marketing 26 (8): 762-77.

Petrick, J. F. 2002. "Development of a Multi-dimensional Scale for Measuring the Perceived Value of a Service.” Journal of Leisure Research 34 (2): 119-34.

Pizam, A., P. E. Tarlow., and J. Bloom. 1997. "Making Tourists Feel Safe: Whose Responsibility Is It?” Journal of Travel Research 36 (1): 23-8.

Ponte, E. B., E. Carvajal-Trujillo., and T. Escobar-Rodríguez. 2015. "Influence of Trust and Perceived Value on the Intention to Purchase Travel Online: Integrating the Effects of Assurance on Trust Antecedents.” Tourism Management 47: 286-302.

Ranaweera, C., and J. Prabhu. 2003. "The Influence of Satisfaction, Trust and Switching Barriers on Customer Retention in a Continuous Purchasing Setting.” International Journal of Service Industry Management 14 (4): 374-95.

Rosenbaum, M. S., and D. L. Spears. 2005. "Who Buys That? Who Does What? Analysis of Cross-cultural Consumption Behaviours among Tourists in Hawaii.” Journal of Vacation Marketing 11 (3): 235-47.

Ruiz-Molina, M. E., and I. Gil-Saura. 2008. "Perceived Value, Customer Attitude and Loyalty in Retailing.” Journal of Retail \& Leisure Property 7 (4): 305-14.

Saayman, M., and A. Saayman. 2012. "Shopping Tourism or Tourists Shopping? A Case Study of South Africa's African Tourism Market.” Tourism Economics 18 (6): 131329.

Sánchez, J., L. Callarisa., R. M. Rodríguez., and M. A. Moliner. 2006. "Perceived Value of the Purchase of a Tourism Product.” Tourism Management 27 (3): 394-409.

Sheth, J. N., B. I. Newman., and B. L. Gross. 1991. "Why We Buy What We Buy: A Theory of Consumption Values.” Journal of Business Research 22 (2): 159-70.

Sirakaya-Turk, E., Y. Ekinci., and D. Martin. 2015. “The Efficacy of Shopping Value in Predicting Destination Loyalty.” Journal of Business Research 68 (9): 1878-85. 
Sirdeshmukh, D., J. Singh., and B. Sabol. 2002. “Consumer Trust, Value, and Loyalty in Relational Exchanges.” Journal of Marketing 66 (1): 15-37.

Sönmez, S. F., and A. R. Graefe. 1998. "Influence of Terrorism Risk on Foreign Tourism Decisions.” Annals of Tourism Research 25 (1): 112-44.

Su, J., and D. Manchala. 1997. "Building Trust for Distributed Commerce Transactions. In Proceedings of the 17th International Conference on Distributed Computing Systems (pp. 36-40). May 1997. Baltimore, U.S.A.

Sun, H., and P. Zhang. 2006. "The Role of Moderating Factors in User Technology Acceptance.” International Journal of Human-Computer Studies 64 (2): 53-78.

Swan, J. E., M. R. Bower., and L. D. Richardson. 1999. "Customer Trust in the Salesperson: An Integrative Review and Meta-analysis of the Empirical Literature.” Journal of Business Research 44, 93-107.

Swanson, K. K., and D. J. Timothy. 2012. "Souvenirs: Icons of Meaning, Commercialization and Commoditization.” Tourism Management 33 (3): 489-99.

Sweeney, J. C., and G. N. Soutar. 2001. "Consumer Perceived Value: The Development of a Multiple Item Scale.” Journal of Retailing 77 (2): 203-20.

Timothy, D. J. 2005. Shopping tourism, retailing, and leisure (Vol. 23). Channel View Publications: Clevedon

Tosun, C., S. P. Temizkan., D. J. Timothy., and A. Fyall. 2007. "Tourist Shopping Experiences and Satisfaction.” International Journal of Tourism Research 9 (2): 87-102.

United Nations World Tourism Organization. 2014. Global report on shopping tourism. Spain: The United Nations World Tourism Organization.

Venkatesh, V., and M. G. Morris. 2000. "Why Don't Men Ever Stop to Ask for Directions? Gender, Social Influence, and Their Role in Technology Acceptance and Usage Behavior.” MIS Quarterly 24 (1): 115-39.

Wong, I. A., and Y. K. P. Wan. 2013. “A Systematic Approach to Scale Development in Tourist Shopping Satisfaction Linking Destination Attributes and Shopping Experience.” Journal of Travel Research 52 (1): 29-41.

Yalch, R., and E. Spangenberg. 1990. "Effects of Store Music on Shopping Behavior.” Journal of Consumer Marketing 7 (2): 55-63.

Yen, C. H., and H. Y. Teng. 2015. "Celebrity Involvement, Perceived Value, and Behavioral Intentions in Popular Media-induced Tourism.” Journal of Hospitality and Tourism Research 39 (2): 225-44. 
Zeithaml, V. A. 1988. “Consumer Perceptions of Price, Quality, and Value: A means-end Model and Synthesis of Evidence.” Journal of Marketing 52 (3): 2-22.

Figure 1. Conceptual Framework 


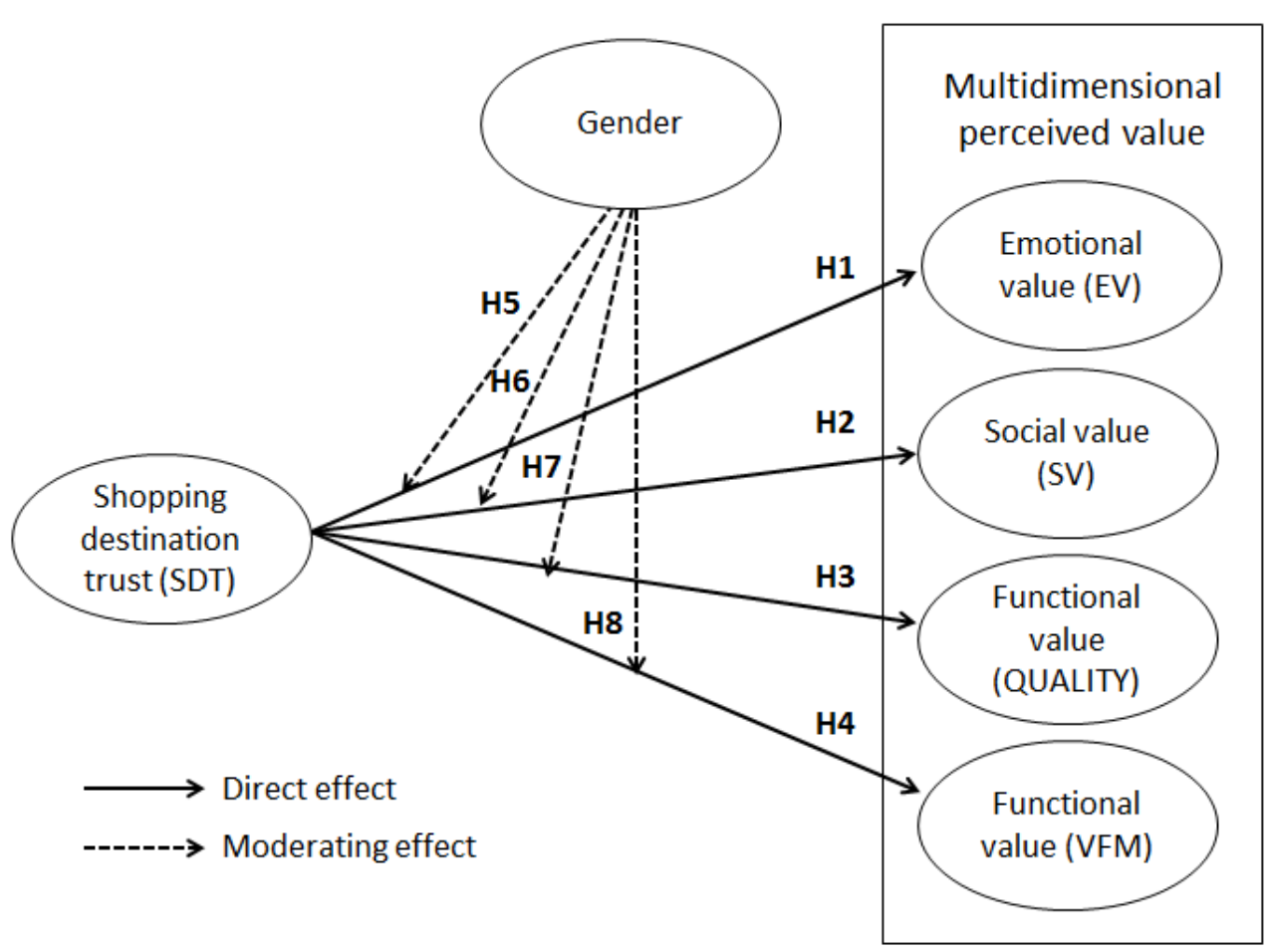

Note: SDT (second-order construct) comprises 9 dimensions including benevolence, integrity, competence, predictability, ability, transaction security, reputation, product, and liking

Table 1. Multidimensional Approach to Perceived Value 


\begin{tabular}{ll}
\hline Author & Dimensions \\
\hline Sheth et al. (1991a, b) & - Social value \\
& - Emotional value \\
& - Functional value \\
& - Epistemic value \\
& - Conditional value \\
& - Cognitive: perceived utility \\
& - Psychological \\
Groth (1995a, b) & - Enternal \\
& - External \\
& - Cognitive \\
- Emotional (psychological) \\
Gronroos (1997) & - Emotional dimension or intrinsic value \\
de Ruyter, Wetzels, Lemmink, and & - Functional dimension or extrinsic value \\
Mattson (1997) & - Logical dimension \\
Sweeney and Soutar (2001) & - Emotional value \\
- Social value \\
- Functional value (price/value for money) \\
- Functional value (quality/performance) \\
Moliner (2006) \\
- Emotional response \\
- Quality \\
- Monetary price \\
- Behavioral price \\
- Reputation \\
- Emotional value \\
- Social value \\
- Functional value: Price \\
- Functional value: Product quality \\
- Functional value: Contact personnel of the travel agency \\
(professionalism) \\
- Functional value: Travel agency (installations). \\
\hline
\end{tabular}

Note: Following Sanchez et al. (2006), the authors have prepared a new summary.

Table 2. Respondent Profiles ( $\mathrm{n}=708)$ 


\begin{tabular}{|c|c|c|c|}
\hline Profile Category & & Frequency & Percentage \\
\hline \multirow[t]{2}{*}{ Gender } & Male & 399 & 56.4 \\
\hline & Female & 309 & 43.6 \\
\hline \multirow[t]{6}{*}{ Age } & 25 or below & 66 & 9.3 \\
\hline & $26-35$ & 122 & 17.2 \\
\hline & $36-45$ & 255 & 36.0 \\
\hline & $46-55$ & 132 & 18.6 \\
\hline & $56-65$ & 76 & 10.7 \\
\hline & 66 or above & 57 & 8.1 \\
\hline \multirow[t]{4}{*}{ Education level } & Middle school & 55 & 7.8 \\
\hline & High school & 219 & 30.9 \\
\hline & Bachelor’s degree & 316 & 44.6 \\
\hline & Graduate/Post-graduate degree & 118 & 16.7 \\
\hline \multirow[t]{5}{*}{ Occupation } & Working & 432 & 61.0 \\
\hline & Housewife & 122 & 17.2 \\
\hline & Student & 61 & 8.6 \\
\hline & Retired & 90 & 12.7 \\
\hline & Others & 3 & 0.4 \\
\hline \multirow[t]{2}{*}{ Nationality } & Chinese & 344 & 48.6 \\
\hline & Non-Chinese & 364 & 51.4 \\
\hline Monthly household & US $\$ 5,000$ or below & 160 & 22.6 \\
\hline \multirow{3}{*}{ Income } & US $\$ 5,001-10,000$ & 396 & 55.9 \\
\hline & US\$10,001-15,000 & 124 & 17.5 \\
\hline & US $\$ 15,001$ or above & 28 & 4 \\
\hline
\end{tabular}

Table 3. Respondents' Travel Activities ( $\mathrm{n}=708$ ) 


\begin{tabular}{|c|c|c|c|}
\hline \multirow{5}{*}{$\begin{array}{l}\text { Frequency of visits to } \\
\text { Hong Kong }\end{array}$} & Never & 309 & 43.6 \\
\hline & $1-3$ times & 293 & 41.4 \\
\hline & 4-6 times & 76 & 10.7 \\
\hline & 7-9 times & 23 & 3.2 \\
\hline & 10 times or more & 7 & 1.0 \\
\hline \multirow[t]{8}{*}{ Main shopping items } & Garments/Fabrics/Shoes & 162 & 22.9 \\
\hline & Leather/Synthetic Goods & 75 & 10.6 \\
\hline & Electrical/Photography Goods & 116 & 16.4 \\
\hline & Jewelry/Watches & 140 & 19.8 \\
\hline & Foodstuff, Alcohol, and Tobacco & 116 & 16.4 \\
\hline & Cosmetics and Skin Care Product/Perfume & 95 & 13.4 \\
\hline & Miscellaneous Consumer Goods & 3 & 0.4 \\
\hline & Other items & 1 & 0.1 \\
\hline \multirow[t]{5}{*}{ Companion } & Alone & 84 & 11.9 \\
\hline & Friends & 165 & 23.3 \\
\hline & Spouse/partner & 295 & 41.7 \\
\hline & Other family members & 59 & 8.3 \\
\hline & Tour group & 105 & 14.8 \\
\hline \multirow[t]{6}{*}{ Travel period } & Day trip & 7 & 1.0 \\
\hline & 1 night 2 days & 39 & 5.5 \\
\hline & 2 nights 3 days & 182 & 25.7 \\
\hline & 3 nights 4 days & 269 & 38.0 \\
\hline & 4 nights 5 days & 144 & 20.3 \\
\hline & 5 nights or more & 67 & 9.5 \\
\hline \multirow{8}{*}{$\begin{array}{l}\text { Shopping expenses } \\
\text { (excluding accommodation } \\
\text { and transport cost) }\end{array}$} & US\$500-999 & 29 & 4.1 \\
\hline & US\$1,000-1,499 & 110 & 15.5 \\
\hline & US\$1,500-1,999 & 37 & 5.2 \\
\hline & US\$2,000-2,499 & 5 & 0.7 \\
\hline & US\$2,500-2,999 & 168 & 23.7 \\
\hline & US\$3,000-3,499 & 73 & 10.3 \\
\hline & US\$3,500-3,999 & 131 & 18.5 \\
\hline & US $\$ 4,000$ or above & 155 & 21.9 \\
\hline
\end{tabular}

Table 4. EFA Results for First Subsample $(n=354)$

\begin{tabular}{lccccc}
\hline Factor & No. of Items & Eigenvalue & \% of Variance & Cumulative \% & $\boldsymbol{\alpha}$ \\
\hline Product & 6 & 22.116 & 34.170 & 34.170 & 0.967 \\
Predictability & 6 & 7.356 & 10.473 & 44.643 & 0.965
\end{tabular}




\begin{tabular}{llllll} 
Competence & 6 & 4.001 & 5.145 & 49.788 & 0.954 \\
Reputation & 6 & 3.105 & 4.648 & 54.436 & 0.958 \\
Quality & 6 & 2.791 & 4.163 & 58.599 & 0.945 \\
Emotion value & 5 & 2.301 & 3.610 & 62.209 & 0.928 \\
Integrity & 4 & 2.167 & 3.100 & 65.309 & 0.945 \\
VFM & 4 & 2.022 & 2.826 & 68.135 & 0.967 \\
Transaction security & 4 & 1.806 & 3.272 & 71.406 & 0.957 \\
Social value & 4 & 1.577 & 2.807 & 74.214 & 0.888 \\
Benevolence & 3 & 1.554 & 2.367 & 76.581 & 0.969 \\
Liking & 3 & 1.323 & 2.393 & 78.974 & 0.956 \\
Ability & 4 & 1.250 & 1.102 & 80.076 & 0.933 \\
\hline
\end{tabular}

Note: Quality refers to functional value (quality/performance) and VFM refers to functional value (price/value for money).

Table 5. CFA Results for Second Subsample (n=354)

\begin{tabular}{|c|c|c|c|c|c|c|}
\hline & & $\begin{array}{l}\text { Factor } \\
\text { loading }\end{array}$ & $\begin{array}{l}\text { Standard } \\
\text { Errors }\end{array}$ & $\begin{array}{c}\text { Critical } \\
\text { Ratio }\end{array}$ & $\begin{array}{l}\text { Composite } \\
\text { reliability }\end{array}$ & $\begin{array}{c}\text { Average Variance } \\
\text { Extracted }\end{array}$ \\
\hline Product (PRO) & & & & & 0.977 & 0.875 \\
\hline PRO5 & PRO & 0.940 & & & & \\
\hline
\end{tabular}




\begin{tabular}{|c|c|c|c|c|c|c|c|}
\hline & & & $\begin{array}{l}\text { Factor } \\
\text { loading }\end{array}$ & $\begin{array}{l}\text { Standard } \\
\text { Errors }\end{array}$ & $\begin{array}{c}\text { Critical } \\
\text { Ratio }\end{array}$ & $\begin{array}{l}\text { Composite } \\
\text { reliability }\end{array}$ & $\begin{array}{c}\text { Average Variance } \\
\text { Extracted }\end{array}$ \\
\hline PRO4 & $<---$ & PRO & 0.935 & 0.027 & 35.239 & & \\
\hline PRO1 & $<---$ & PRO & 0.947 & 0.027 & 37.101 & & \\
\hline PRO3 & $<---$ & PRO & 0.937 & 0.029 & 35.519 & & \\
\hline PRO2 & $<---$ & PRO & 0.949 & 0.025 & 37.517 & & \\
\hline PRO6 & $<---$ & PRO & 0.904 & 0.030 & 31.029 & & \\
\hline \multicolumn{6}{|c|}{ Predictability (PRE) } & 0.971 & 0.848 \\
\hline PRE5 & $<---$ & PRE & 0.954 & & & & \\
\hline PRE1 & $<---$ & PRE & 0.940 & 0.026 & 38.380 & & \\
\hline PRE3 & $<---$ & PRE & 0.942 & 0.026 & 38.843 & & \\
\hline PRE2 & $<---$ & PRE & 0.943 & 0.022 & 38.962 & & \\
\hline PRE4 & $<---$ & PRE & 0.921 & 0.026 & 34.979 & & \\
\hline PRE6 & $<---$ & PRE & 0.820 & 0.032 & 24.235 & & \\
\hline \multicolumn{6}{|c|}{ Reputation (REP) } & 0.965 & 0.823 \\
\hline REP1 & $<---$ & REP & 0.937 & & & & \\
\hline REP4 & $<---$ & REP & 0.922 & 0.029 & 32.645 & & \\
\hline REP5 & $<---$ & REP & 0.944 & 0.026 & 35.666 & & \\
\hline REP2 & $<---$ & REP & 0.908 & 0.029 & 30.883 & & \\
\hline REP6 & $<---$ & REP & 0.820 & 0.034 & 23.301 & & \\
\hline REP3 & $<---$ & REP & 0.905 & 0.029 & 30.569 & & \\
\hline \multicolumn{6}{|c|}{ Competence (COM) } & 0.937 & 0.714 \\
\hline COM4 & $<---$ & COM & 0.890 & & & & \\
\hline СOM3 & $<---$ & COM & 0.930 & 0.037 & 27.801 & & \\
\hline COM1 & $<---$ & COM & 0.919 & 0.037 & 27.025 & & \\
\hline COM5 & $<---$ & COM & 0.811 & 0.046 & 20.589 & & \\
\hline COM2 & $<---$ & COM & 0.721 & 0.053 & 16.774 & & \\
\hline COM6 & $<---$ & COM & 0.778 & 0.040 & 19.091 & & \\
\hline \multicolumn{6}{|c|}{ Functional value-quality/performance (QUALITY) } & 0.935 & 0.708 \\
\hline quality2 & $<---$ & $\begin{array}{l}\text { QUALI } \\
\text { TY }\end{array}$ & 0.957 & & & & \\
\hline quality1 & $<---$ & $\begin{array}{l}\text { QUALI } \\
\text { TY }\end{array}$ & 0.944 & 0.028 & 38.126 & & \\
\hline quality6 & $<---$ & $\begin{array}{l}\text { QUALI } \\
\text { TY }\end{array}$ & 0.798 & 0.038 & 22.448 & & \\
\hline quality3 & $<---$ & $\begin{array}{l}\text { QUALI } \\
\text { TY }\end{array}$ & 0.809 & 0.034 & 23.183 & & \\
\hline quality4 & $<---$ & $\begin{array}{l}\text { QUALI } \\
\text { TY }\end{array}$ & 0.755 & 0.044 & 19.916 & & \\
\hline quality5 & $<---$ & $\begin{array}{l}\text { QUALI } \\
\text { TY }\end{array}$ & 0.763 & 0.043 & 20.341 & & \\
\hline \multicolumn{6}{|c|}{ Emotional value (EV) } & 0.959 & 0.826 \\
\hline EV3 & $<---$ & EV & 0.846 & & & & \\
\hline EV4 & $<---$ & $\mathrm{EV}$ & 0.930 & 0.045 & 24.650 & & \\
\hline EV5 & $<---$ & EV & 0.925 & 0.046 & 24.396 & & \\
\hline EV2 & $<---$ & $\mathrm{EV}$ & 0.904 & 0.047 & 23.300 & & \\
\hline EV1 & $<---$ & $\mathrm{EV}$ & 0.936 & 0.046 & 24.986 & & \\
\hline \multicolumn{6}{|c|}{ Transaction security (TS) } & 0.965 & 0.872 \\
\hline TS3 & $<---$ & TS & 0.931 & & & & \\
\hline TS1 & $<---$ & TS & 0.944 & 0.032 & 34.675 & & \\
\hline TS2 & $<---$ & TS & 0.910 & 0.036 & 30.475 & & \\
\hline TS4 & $<---$ & TS & 0.950 & 0.033 & 35.520 & & \\
\hline \multicolumn{6}{|c|}{ Functional value-price/value for money (VFM) } & 0.968 & 0.885 \\
\hline VFM4 & $<---$ & VFM & 0.966 & & & & \\
\hline
\end{tabular}




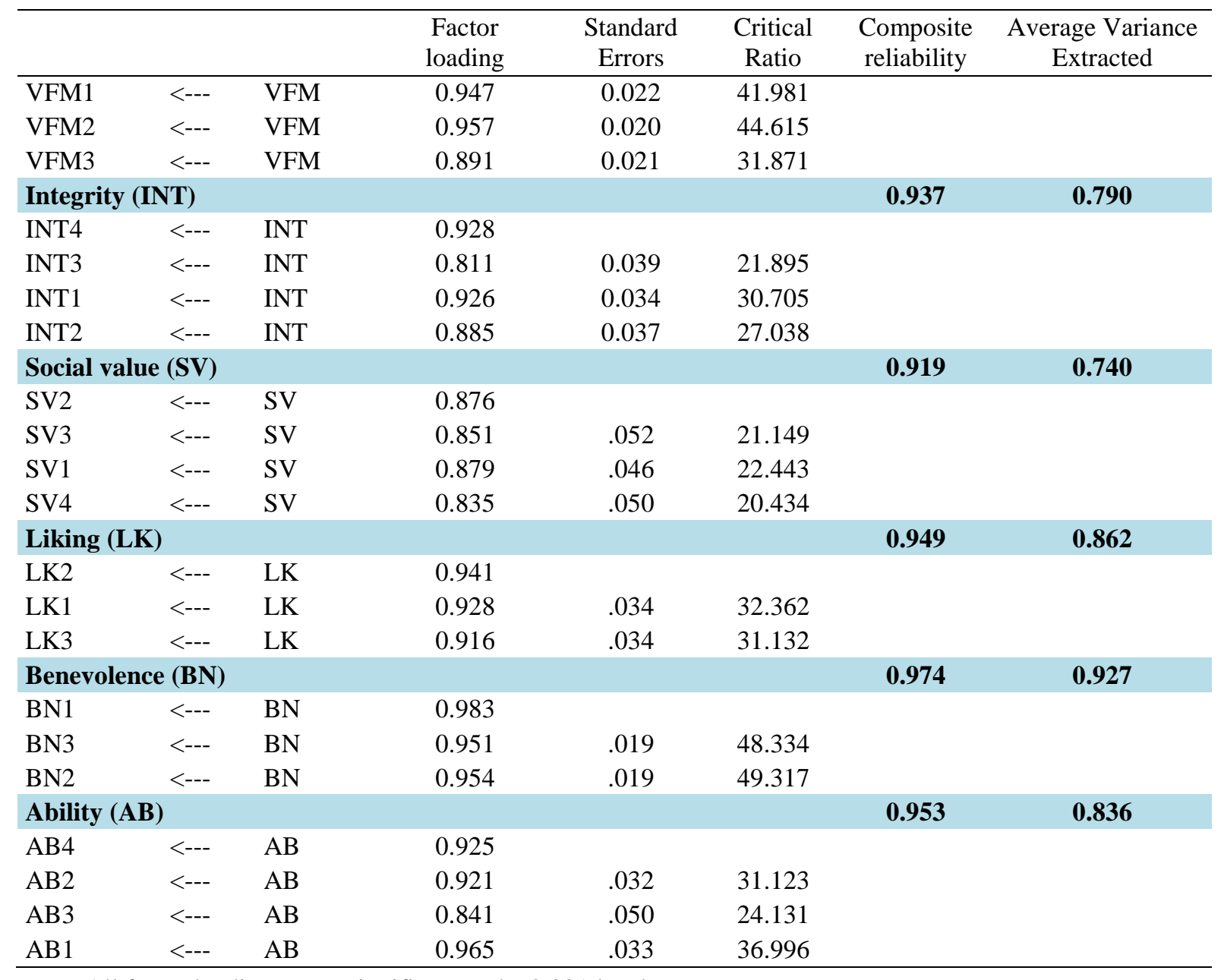

Note: All factor loadings were significant at the 0.001 level. 
Table 6. Discriminant Validity $(\mathrm{n}=354)$

\begin{tabular}{|c|c|c|c|c|c|c|c|c|c|c|c|c|c|}
\hline & $\mathbf{B N}$ & PRO & PRE & REP & COM & QUALITY & $\mathbf{E V}$ & TS & VFM & INT & SV & LK & AB \\
\hline BN & 0.963 & & & & & & & & & & & & \\
\hline PRO & 0.465 & 0.935 & & & & & & & & & & & \\
\hline PRE & 0.567 & 0.397 & 0.921 & & & & & & & & & & \\
\hline REP & 0.505 & 0.519 & 0.583 & 0.907 & & & & & & & & & \\
\hline COM & 0.490 & 0.478 & 0.418 & 0.481 & 0.845 & & & & & & & & \\
\hline QUALITY & 0.250 & 0.076 & 0.099 & 0.069 & 0.059 & 0.842 & & & & & & & \\
\hline EV & 0.347 & 0.144 & 0.233 & 0.125 & 0.147 & 0.585 & 0.909 & & & & & & \\
\hline TS & 0.494 & 0.566 & 0.450 & 0.518 & 0.483 & 0.078 & 0.133 & 0.934 & & & & & \\
\hline VFM & 0.253 & 0.057 & 0.142 & 0.083 & 0.040 & 0.592 & 0.658 & 0.038 & 0.941 & & & & \\
\hline INT & 0.581 & 0.379 & 0.497 & 0.465 & 0.613 & 0.246 & 0.249 & 0.478 & 0.205 & 0.889 & & & \\
\hline SV & 0.249 & 0.029 & 0.219 & 0.016 & 0.073 & 0.533 & 0.610 & 0.025 & 0.505 & 0.275 & 0.860 & & \\
\hline LK & 0.480 & 0.466 & 0.528 & 0.548 & 0.420 & 0.171 & 0.186 & 0.587 & 0.182 & 0.420 & 0.159 & 0.928 & \\
\hline AB & 0.709 & 0.644 & 0.666 & 0.716 & 0.671 & 0.160 & 0.198 & 0.741 & 0.133 & 0.659 & 0.145 & 0.702 & 0.914 \\
\hline
\end{tabular}

Note: BN- benevolence; PRO-product; PRE-predictability; REP-reputation; COM-competence; QUALfunctional value (quality/performance); EV-emotional value; TS- transaction security; VFM- functional value (price/value for money), INT-integrity; SV-social value; LK-liking; AB-ability 
Table 7. Results of First-order CFA ( $n=708)$

\begin{tabular}{|c|c|c|c|c|c|c|c|}
\hline & & & $\begin{array}{l}\text { Factor } \\
\text { loading }\end{array}$ & $\begin{array}{l}\text { Standard } \\
\text { Errors }\end{array}$ & $\begin{array}{c}\text { Critical } \\
\text { Ratio }\end{array}$ & $\begin{array}{l}\text { Composite } \\
\text { reliability }\end{array}$ & $\begin{array}{c}\text { Average Variance } \\
\text { Extracted }\end{array}$ \\
\hline \multicolumn{4}{|c|}{ Product (PRO) } & & & 0.972 & 0.855 \\
\hline PRO5 & $<---$ & PRO & 0.914 & & & & \\
\hline PRO4 & $<---$ & PRO & 0.920 & 0.023 & 42.491 & & \\
\hline PRO2 & $<---$ & PRO & 0.947 & 0.020 & 46.776 & & \\
\hline PRO1 & $<---$ & PRO & 0.947 & 0.022 & 46.787 & & \\
\hline PRO3 & $<---$ & PRO & 0.935 & 0.023 & 44.835 & & \\
\hline PRO6 & $<---$ & PRO & 0.882 & 0.024 & 37.657 & & \\
\hline \multicolumn{4}{|c|}{ Predictability (PRE) } & & & 0.969 & 0.838 \\
\hline PRE1 & $<---$ & PRE & 0.934 & & & & \\
\hline PRE5 & $<---$ & PRE & 0.945 & 0.020 & 50.281 & & \\
\hline PRE2 & $<---$ & PRE & 0.938 & 0.018 & 48.779 & & \\
\hline PRE3 & $<---$ & PRE & 0.934 & 0.020 & 48.136 & & \\
\hline PRE4 & $<---$ & PRE & 0.917 & 0.020 & 44.905 & & \\
\hline PRE6 & $<---$ & PRE & 0.818 & 0.024 & 32.693 & & \\
\hline \multicolumn{4}{|c|}{ Reputation (REP) } & & & 0.962 & 0.810 \\
\hline REP1 & $<---$ & REP & 0.937 & & & & \\
\hline REP5 & $<---$ & REP & 0.927 & 0.020 & 46.888 & & \\
\hline REP4 & $<---$ & REP & 0.907 & 0.021 & 43.444 & & \\
\hline REP2 & $<---$ & REP & 0.901 & 0.021 & 42.553 & & \\
\hline REP3 & $<---$ & REP & 0.912 & 0.020 & 44.287 & & \\
\hline REP6 & $<---$ & REP & 0.810 & 0.024 & 31.968 & & \\
\hline \multicolumn{4}{|c|}{ Competence (COM) } & & & 0.946 & 0.744 \\
\hline COM3 & $<---$ & COM & 0.912 & & & & \\
\hline COM4 & $<---$ & $\mathrm{COM}$ & 0.893 & 0.026 & 37.866 & & \\
\hline COM1 & $<---$ & $\mathrm{COM}$ & 0.916 & 0.024 & 40.675 & & \\
\hline COM5 & $<---$ & COM & 0.821 & 0.030 & 31.070 & & \\
\hline COM2 & $<---$ & $\mathrm{COM}$ & 0.805 & 0.032 & 29.891 & & \\
\hline COM6 & $<---$ & $\mathrm{COM}$ & 0.822 & 0.026 & 31.183 & & \\
\hline
\end{tabular}

$\begin{array}{lll}\text { Functional value-quality/performance (QUALITY) } & 0.941 & 0.729\end{array}$

$\begin{array}{llllll}\text { quality1 <--- } & \text { QUALITY } & 0.940 & & \\ \text { quality2 } & <--- & \text { QUALITY } & 0.947 & 0.018 & 50.686 \\ \text { quality6 }<--- & \text { QUALITY } & 0.823 & 0.025 & 33.098 \\ \text { quality3 <--- } & \text { QUALITY } & 0.842 & 0.023 & 35.019 \\ \text { quality4 <--- } & \text { QUALITY } & 0.782 & 0.028 & 29.579 \\ \text { quality5 }<--- & \text { QUALITY } & 0.771 & 0.028 & 28.694\end{array}$

\begin{tabular}{|c|c|c|c|c|c|c|c|}
\hline \multicolumn{6}{|c|}{ Emotional value (EV) } & \multirow[t]{2}{*}{0.947} & \multirow[t]{2}{*}{0.781} \\
\hline EV5 & $<---$ & EV & 0.896 & & & & \\
\hline EV4 & $<---$ & $\mathrm{EV}$ & 0.901 & 0.026 & 36.886 & & \\
\hline EV2 & $<---$ & $\mathrm{EV}$ & 0.879 & 0.027 & 34.784 & & \\
\hline EV1 & $<---$ & $\mathrm{EV}$ & 0.906 & 0.027 & 37.306 & & \\
\hline EV3 & $<---$ & $\mathrm{EV}$ & 0.834 & 0.029 & 31.057 & & \\
\hline \multicolumn{6}{|c|}{ Transaction security (TS) } & 0.961 & 0.862 \\
\hline TS3 & $<---$ & TS & 0.924 & & & & \\
\hline TS1 & $<---$ & TS & 0.945 & 0.024 & 47.543 & & \\
\hline TS4 & $<---$ & TS & 0.943 & 0.025 & 47.217 & & \\
\hline TS2 & $<---$ & TS & 0.901 & 0.027 & 40.704 & & \\
\hline \multicolumn{6}{|c|}{ Functional value- price/value for money (VFM) } & 0.968 & 0.882 \\
\hline VFM4 & $<---$ & VFM & 0.967 & & & & \\
\hline VFM2 & $<---$ & VFM & 0.962 & 0.014 & 65.991 & & \\
\hline
\end{tabular}




\begin{tabular}{|c|c|c|c|c|c|c|}
\hline & & $\begin{array}{l}\text { Factor } \\
\text { loading }\end{array}$ & $\begin{array}{l}\text { Standard } \\
\text { Errors }\end{array}$ & $\begin{array}{c}\text { Critical } \\
\text { Ratio }\end{array}$ & $\begin{array}{l}\text { Composite } \\
\text { reliability }\end{array}$ & $\begin{array}{c}\text { Average Variance } \\
\text { Extracted }\end{array}$ \\
\hline VFM1 & $<---\quad$ VFM & 0.951 & 0.016 & 61.597 & & \\
\hline VFM3 & $<---\quad$ VFM & 0.874 & 0.017 & 42.497 & & \\
\hline \multicolumn{5}{|c|}{ Integrity (INT) } & 0.941 & 0.801 \\
\hline INT4 & $<---\quad$ INT & 0.925 & & & & \\
\hline INT3 & $<---\quad$ INT & 0.820 & 0.028 & 31.549 & & \\
\hline INT1 & $<---\quad$ INT & 0.919 & 0.025 & 42.222 & & \\
\hline INT2 & $<---\quad$ INT & 0.912 & 0.025 & 41.241 & & \\
\hline \multicolumn{5}{|c|}{ Social value (SV) } & 0.906 & 0.708 \\
\hline SV2 & $<---\quad$ SV & 0.856 & & & & \\
\hline SV3 & $<---\quad$ SV & 0.840 & 0.039 & 27.557 & & \\
\hline SV1 & $<---\quad$ SV & 0.848 & 0.035 & 27.973 & & \\
\hline SV4 & $<---\quad$ SV & 0.821 & 0.038 & 26.562 & & \\
\hline \multicolumn{5}{|c|}{ Benevolence (BN) } & 0.973 & 0.923 \\
\hline BN1 & $<---\quad \mathrm{BN}$ & 0.984 & & & & \\
\hline BN2 & $<---\quad B N$ & 0.953 & 0.014 & 68.982 & & \\
\hline BN3 & $<---\quad B N$ & 0.944 & 0.013 & 64.865 & & \\
\hline \multicolumn{5}{|c|}{ Liking (LK) } & 0.952 & 0.869 \\
\hline LK3 & $<---\quad$ LK & 0.935 & & & & \\
\hline LK2 & $<---\quad$ LK & 0.935 & 0.020 & 46.299 & & \\
\hline LK1 & $<---\quad$ LK & 0.927 & 0.022 & 45.164 & & \\
\hline \multicolumn{5}{|c|}{ Ability (AB) } & 0.947 & 0.816 \\
\hline $\mathrm{AB} 4$ & $<---\quad A B$ & 0.910 & & & & \\
\hline AB2 & $<---\quad A B$ & 0.916 & 0.024 & 40.712 & & \\
\hline AB3 & $<---\quad A B$ & 0.841 & 0.037 & 32.862 & & \\
\hline $\mathrm{AB} 1$ & $<---\quad A B$ & 0.944 & 0.027 & 44.532 & & \\
\hline
\end{tabular}

Note: All factor loadings were significant at the 0.001 level. 
Table 8 Discriminant Validity of First-order Measurement Model (n=708)

\begin{tabular}{llllllllllllll}
\hline & LK & PRO & PRE & REP & COM & QUALITY & EV & TS & VFM & INT & SV & BN & AB \\
\hline LK & $\mathbf{0 . 9 3 2}$ & & & & & & & & & & & & \\
PRO & 0.509 & $\mathbf{0 . 9 2 4}$ & & & & & & & & & & & \\
PRE & 0.524 & 0.460 & $\mathbf{0 . 9 1 5}$ & & & & & & & & & & \\
REP & 0.492 & 0.527 & 0.561 & $\mathbf{0 . 9 0 0}$ & & & & & & & & & \\
COM & 0.463 & 0.485 & 0.473 & 0.416 & $\mathbf{0 . 8 6 3}$ & & & & & & & & \\
QUALITY & 0.173 & 0.136 & 0.097 & 0.119 & 0.191 & $\mathbf{0 . 8 5 4}$ & & & & & & & \\
EV & 0.209 & 0.199 & 0.241 & 0.197 & 0.179 & 0.482 & $\mathbf{0 . 8 8 4}$ & & & & & & \\
TS & 0.500 & 0.486 & 0.466 & 0.489 & 0.525 & 0.151 & 0.191 & $\mathbf{0 . 9 2 8}$ & & & & & \\
VFM & 0.122 & 0.081 & 0.104 & 0.093 & 0.136 & 0.554 & 0.567 & 0.069 & $\mathbf{0 . 9 3 9}$ & & & & \\
INT & 0.451 & 0.403 & 0.508 & 0.481 & 0.595 & 0.240 & 0.287 & 0.536 & 0.211 & $\mathbf{0 . 8 9 5}$ & & & \\
SV & 0.137 & 0.106 & 0.176 & 0.077 & 0.118 & 0.498 & 0.522 & 0.083 & 0.469 & 0.254 & $\mathbf{0 . 8 4 1}$ & & \\
BN & 0.456 & 0.453 & 0.549 & 0.402 & 0.544 & 0.242 & 0.308 & 0.468 & 0.183 & 0.491 & 0.153 & $\mathbf{0 . 9 6 0}$ & \\
AB & 0.651 & 0.673 & 0.662 & 0.649 & 0.676 & 0.222 & 0.256 & 0.654 & 0.180 & 0.680 & 0.185 & 0.672 & $\mathbf{0 . 9 0 4}$ \\
\hline
\end{tabular}

Note: LK-liking; PRO-product; PRE-predictability; REP-reputation; COM-competence; QUALITY-functional value (quality/performance); EV-emotional value; TS- transaction security; VFM- functional value (price/value for money), INT- integrity; SV- social value, BN- benevolence; AB- ability 
Table 9 Results of Second-order CFA $(n=708)$

\begin{tabular}{|c|c|c|c|c|c|c|c|}
\hline & & & $\begin{array}{l}\text { Factor } \\
\text { loading }\end{array}$ & $\begin{array}{l}\text { Standard } \\
\text { Errors }\end{array}$ & $\begin{array}{c}\text { Critical } \\
\text { Ratio }\end{array}$ & $\begin{array}{l}\text { Composite } \\
\text { reliability }\end{array}$ & $\begin{array}{c}\text { Average Variance } \\
\text { Extracted }\end{array}$ \\
\hline \multicolumn{6}{|c|}{ Shopping destination trust (SDT) } & 0.911 & 0.536 \\
\hline PRO & $<---$ & SDT & 0.691 & 0.051 & 19.737 & & \\
\hline PRE & $<---$ & SDT & 0.711 & 0.051 & 20.780 & & \\
\hline REP & $<---$ & SDT & 0.684 & 0.049 & 19.726 & & \\
\hline $\mathrm{COM}$ & $<---$ & SDT & 0.715 & 0.046 & 20.405 & & \\
\hline TS & $<---$ & SDT & 0.698 & 0.045 & 20.044 & & \\
\hline INT & $<---$ & SDT & 0.716 & 0.041 & 20.606 & & \\
\hline $\mathrm{BN}$ & $<---$ & SDT & 0.701 & 0.052 & 21.212 & & \\
\hline LK & $<---$ & SDT & 0.689 & 0.052 & 19.743 & & \\
\hline $\mathrm{AB}$ & $<---$ & SDT & 0.947 & & & & \\
\hline \multicolumn{6}{|c|}{ Functional value- quality/performance (QUALITY) } & 0.941 & 0.729 \\
\hline quality1 & $<---$ & QUALITY & 0.940 & & & & \\
\hline quality2 & $<---$ & QUALITY & 0.947 & 0.018 & 50.559 & & \\
\hline quality6 & $<---$ & QUALITY & 0.823 & 0.025 & 33.133 & & \\
\hline quality3 & $<---$ & QUALITY & 0.842 & 0.023 & 35.037 & & \\
\hline quality4 & $<---$ & QUALITY & 0.783 & 0.028 & 29.594 & & \\
\hline quality5 & $<---$ & QUALITY & 0.771 & 0.028 & 28.703 & & \\
\hline \multicolumn{6}{|c|}{ Emotional value (EV) } & 0.947 & 0.781 \\
\hline EV5 & $<---$ & EV & 0.896 & & & & \\
\hline EV4 & $<---$ & EV & 0.901 & 0.026 & 36.899 & & \\
\hline EV2 & $<---$ & $\mathrm{EV}$ & 0.880 & 0.027 & 34.892 & & \\
\hline EV1 & $<---$ & EV & 0.905 & 0.027 & 37.238 & & \\
\hline EV3 & $<---$ & EV & 0.834 & 0.029 & 31.025 & & \\
\hline \multicolumn{6}{|c|}{ Functional value-price/value for money (VFM) } & 0.968 & 0.882 \\
\hline VFM4 & $<---$ & VFM & 0.967 & & & & \\
\hline VFM2 & $<---$ & VFM & 0.961 & 0.014 & 65.978 & & \\
\hline VFM1 & $<---$ & VFM & 0.951 & 0.016 & 61.648 & & \\
\hline VFM3 & $<---$ & VFM & 0.874 & 0.017 & 42.507 & & \\
\hline \multicolumn{6}{|c|}{ Social value } & 0.911 & 0.707 \\
\hline SV2 & $<---$ & SV & 0.858 & & & & \\
\hline SV3 & $<---$ & SV & 0.839 & 0.039 & 27.573 & & \\
\hline SV1 & $<---$ & SV & 0.848 & 0.035 & 28.083 & & \\
\hline SV4 & $<---$ & SV & 0.819 & 0.038 & 26.585 & & \\
\hline
\end{tabular}

Note: All factor loadings were significant at the 0.001 level.

Table 10 Discriminant Validity of Second-order Measurement Model (n=708) 


\begin{tabular}{lccccc}
\hline & SV & QUALITY & EV & VFM & SDT \\
\hline SV & $\mathbf{0 . 8 4 1}$ & & & & \\
QUALITY & 0.498 & $\mathbf{0 . 8 5 4}$ & & & \\
EV & 0.522 & 0.482 & $\mathbf{0 . 8 8 4}$ & & \\
VFM & 0.469 & 0.554 & 0.567 & $\mathbf{0 . 9 3 9}$ & \\
SDT & 0.197 & 0.238 & 0.300 & 0.184 & $\mathbf{0 . 7 3 2}$ \\
\hline
\end{tabular}

Note: SV- social value; QUALITY-functional value (quality/performance); EV- emotional value; VFM-functional value (price/value for money); SDT- shopping destination trust

Table 11. Direct Path Results for the Structural Model 


\begin{tabular}{lcccccc}
\hline \multicolumn{2}{l}{ Hypothesis/path } & & & Path coefficient & t-value & Results \\
\hline H1: & EV & $\leftarrow$ & SDT & 0.326 & $7.925^{* * *}$ & Supported \\
H2: & SV & $\leftarrow$ & SDT & 0.226 & $5.479^{* * *}$ & Supported \\
H3: & QUALITY & $\leftarrow$ & SDT & 0.266 & $6.610^{* * *}$ & Supported \\
H4: & VFM & $\leftarrow$ & SDT & 0.216 & $5.335^{* * *}$ & Supported \\
\hline
\end{tabular}

Notes: 1) ${ }^{* * *}$ p-value $<0.01$; ** p-value $<0.05{ }^{*}$ p-value $<0.10$; 2) SDT -shopping destination trust, $\quad$ EVemotional value, SV- social value, QUALITY- functional value (quality/performance), and VFM- functional value (price/value for money)

Table 12. Moderating Effect of Gender 


\begin{tabular}{lccccccc}
\hline \multicolumn{1}{l}{ Hypothesis/path } & & & Male & Female & z-score & Results \\
\hline H5: & EV & $\leftarrow$ & SDT & $0.260^{* * *}$ & $0.283^{* * *}$ & -0.333 & Not Supported \\
H6: & SV & $\leftarrow$ & SDT & $0.207^{* * *}$ & $0.159^{* * *}$ & 0.707 & Not Supported \\
H7: & QUALIT & $\leftarrow$ & SDT & $0.393^{* * *}$ & $0.072^{* *}$ & $4.208^{* * *}$ & Supported \\
H8: & Y & & & & & \\
\end{tabular}

Notes: 1) ${ }^{* * *}$ p-value $<0.01$; ${ }^{* *}$ p-value $<0.05$; ${ }^{*}$ p-value $<0.10$; 2) SDT -shopping destination trust, EVemotional value, SV- social value, QUALITY- functional value (quality/performance), and VFM- functional value (price/value for money) 